\title{
Психологический стресс
}

\section{и ревматоидный артрит - интерференция патогенетических механизмов}

\author{
Туаева Н.0., ${ }^{1,2}$ Носырев А.Е.', Ренадино И., ${ }^{1,3}$, Арлеевская М.И.
}

\begin{abstract}
'Казанская государственная академия - филиал ФГБОУ ДПО «Российская медицинская академия непрерывного профессионального образования» Минздрава России, Казань, Россия; ${ }^{\circ}$ ФГАОУ ВО «Первый Московский государственный медицинский университет им. И.М. Сеченова» Минздрава России (Сеченовский Университет), Москва, Россия; ${ }^{3}$ Laboratory of Immunology and Immunotherapy, INSERM U1227, Hospital Morvan, Centre Hospitalier Regional Universitaire (CHU) de Brest, Brest, France ${ }^{1} 420012$, Казань, ул. Муштари, 11; ${ }^{2119991, ~ М о с к в а, ~}$ ул. Трубецкая, 8, стр. 2; ${ }^{3} 2$ Avenue Foch, CHRU Morvan, 29609 Brest, France
\end{abstract}

\section{'Kazan State Medical} Academy - Branch Campus of Russian Medical Academy of Postgraduate Education, Ministry of Health of Russia, Russia, Kazan, Russia; ${ }^{1}$ I.M. Sechenov First Moscow State Medical University, Ministry of Health of Russia (Sechenov University), Moscow, Russia; 'Laboratory of Immunology and Immunotherapy, INSERM U1227, Hospital Morvan, Centre Hospitalier Regional Universitaire (CHU) de Brest, Brest, France

111, Moushtary St., Kazan 420012; ${ }^{2} 8$, Trubetskaya

St., Build. 2, Moscow 119991; ${ }^{2} 2$ Avenue Foch, CHRU Morvan, 29609 Brest, France

Контакты: Наталья Олеговна Туаева;

Natalya.Tuaeva@gmail.com

Contacts: Natalia Tuaeva; Natalya.Tuaeva@gmail.com

Поступила 31.07.18

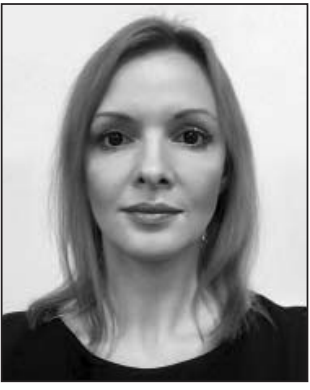

Туаева H.О. научный сотрудник ЦНИЛ Казанской государственной академии, химик-эксперт центра биоаналитических исследований и молекулярного дизайна (ЦБИиМД) Первого МГМУ им. И.М. Сеченова, канд. биол. наук

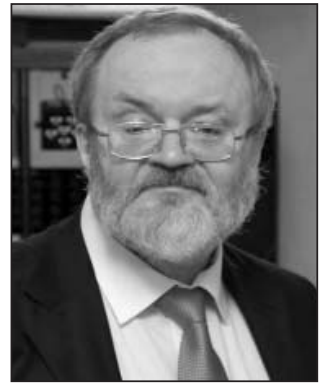

Носырев A.E. руководитель ЦБИиМД

Первого МГМУ им. И.М. Сеченова, канд. техн. наук

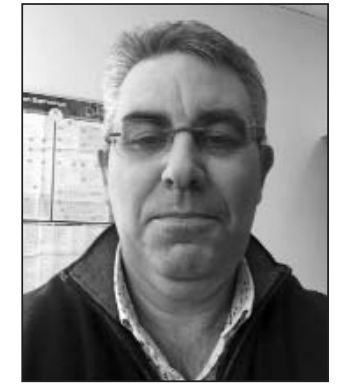

Ренадино И. профессор,

старший научный сотрудник ЦНИЛ КГМА, заведующий лабораторией иммунологии и иммунотерапии Университета Бреста, Франция

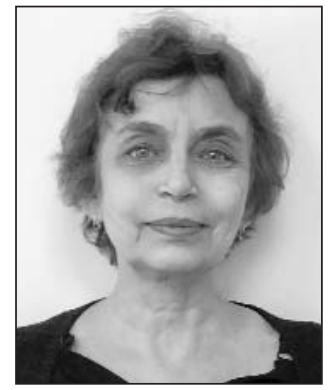

Арлеевская М.И. старший научный сотрудник ЦНИЛ Казанской государственной академии, канд. мед. наук

Проанализированы молекулярные механизмы развития нормального и патологического нейроэндокринного и иммунного адаптивного ответа на психологический (ментальный) стресс с точки зрения его возможной провоцирующей роли в развитии ревматоидного артрита (РА). При детальном анализе выявляется синергизм механизмов, провоцирующих развитие патологического антистрессового адаптивного ответа и РА. Возможно, у лиц группы риска развития РА минимальные и малозаметные для индивидуума стрессовые ситуации, периодически провоцирующие продолжительную продукцию провоспалительных цитокинов, могут, в конце концов, привести к развитию ревматического заболевания.

Ключевые слова: ревматоидный артрит; психологический стресс; аллостаз; эустресс; дистресс.

Для ссылки: Туаева НО, Носырев АЕ, Ренадино И, Арлеевская МИ. Психологический стресс и ревматоидный артрит - интерференция патогенетических механизмов. Научно-практическая ревматология. 2019;57(1):83-90.

\section{PSYCHOLOGICAL STRESS AND RHEUMATOID ARTHRITIS - INTERFERENCE OF PATHOGENETIC MECHANISMS \\ Tuaeva N.O. ${ }^{1,2}$, Nosyrev A.E. ${ }^{2}$, Renaudineau Y. ${ }^{1,3}$, Arleevskaya M.I. ${ }^{1}$}

Molecular mechanisms of development of normal and pathological neuroendocrine and immune adaptive response to psychological (mental) stress are analyzed considering its possible provoking role in the development of rheumatoid arthritis (RA). A detailed analysis reveals the synergism of mechanisms that provoke the development of pathological anti-stress adaptive response and RA. It is possible that in persons at risk of developing RA minimal and unobtrusive for the individual stressful situations, periodically provoking prolonged production of pro-inflammatory cytokines, can, finally, lead to the development of rheumatic disease.

Keywords: rheumatoid arthritis; psychological stress; allostasis; eustress; distress.

For reference: Tuaeva NO, Nosyrev AE, Renaudineau Y, Arleevskaya MI. Psychological stress and rheumatoid arthritis - interference of pathogenetic mechanisms. Nauchno-Prakticheskaya Revmatologiya = Rheumatology Science and Practice. 2019;57(1):83-90 (In Russ.).

doi: 10.14412/1995-4484-2019-83-90

Ревматоидный артрит (РА), как и большинство других аутоиммунных и воспалительных процессов, имеет многофакторную природу: 30-60\% риска его развития обусловлено генетической предраспо- ложенностью, 40-70\% - связано с влиянием факторов окружающей среды [1]. При этом ни одна из ассоциированных с РА мутаций генов и ни один из средовых факторов по отдельности не определяют разви- 
тие заболевания и его тяжесть. Лишь совокупность средовых факторов, последовательно или одновременно воздействующих на места наименьшего сопротивления, подталкивает развертывание основных механизмов патогенеза. При этом, учитывая наличие различных фенотипов заболевания, разные варианты сочетания эндои экзогенных факторов могут быть уникальны не только для данной популяции, но даже для каждого индивидуума в популяции [2].

В современных условиях одним из важнейших факторов цивилизационной нагрузки на организм человека является психологический (ментальный) стресс. Согласно Гансу Селье, стресс - это адаптивная нейрогуморальная реакция организма на любые нарушения либо угрозы нарушения гомеостаза, направленная на его восстановление [3]. Данные литературы, касающиеся участия психологического стресса в развитии РА, противоречивы. В российском исследовании $47,7 \%$ больных указали психоэмоциональный фактор в качестве причины развития PA [4]. По данным J.G. Hanly и соавт. [5], 66\% больных РА до манифестации артрита страдали депрессивными расстройствами. Исследование M. Lu и соавт. [6], включившее 8331 больного РА и 15456 человек без РА (база данных National Health Insurance Research Database of Taiwan), показало, что заболеваемость РА среди лиц, страдающих депрессией, выше, чем в популяции. В свою очередь, частота депрессии у больных РА выше, чем у пациентов с другими заболеваниями. А. Farmer и соавт. [7] в исследовании, проведенном в больших когортах людей, страдавших и не страдавших (контроль) рецидивирующей депрессией, обнаружили, что частота РА у лиц с эмоциональным неблагополучием в два раза превышает таковую в контроле. В то же время исследование, охватившее 7076 респондентов, показало, что частота РА у лиц с расстройствами настроения и тревогой в анамнезе не превышала таковую в контроле [8]. По данным M. Söderlin и соавт. [9], психологическую травму (острый стресс) как причину развития РА отметили лишь 4,4\% пациентов. Еще 4,2\% упомянули физическую травму, и $2,8 \%$ больных предполагали, что их заболевание является следствием какого-либо хирургического вмешательства. Однако стоит отметить, что в данном опросе не учитывали хронический бытовой психологический стресс и депрессию.

A. Rezvani и соавт. [10] исследовали взаимосвязь темперамента с РА в турецкой популяции. Оказалось, что 59\% больных РА обладали депрессивным темпераментом. В 9,3\% случаев депрессивный темперамент сопровождался повышенной раздражительностью. В когорте соматически здоровых лиц депрессивный темперамент обнаруживался лишь в $3 \%$ случаев. На основании приведенных данных можно предположить, что активность РА и эмоциональный стресс потенцируют друг друга, будучи одновременно и движущей силой, и следствием обоих этих процессов. Поэтому для осознания роли стресса в патогенезе РА представляется полезным поиск точек пересечения механизмов этих двух состояний.

\section{Механизмы развития адаптивного ответа на эустресс}

Эустресс - это благоприятный стресс, провоцирующий развитие защитной адаптивной реакции на стрессоры для мобилизации психических и физиологи- ческих резервов организма с целью разрешения возникшей ситуации [3]. Молекулярные механизмы гуморальной реакции на эустресс - это сложная, сбалансированная система тормозных воздействий и противовесов, в которой функционирует множество разнонаправленно действующих факторов. Вовлечение тех или иных факторов зависит от характера стресса [11]. Мы остановимся на механизмах, которые могут иметь значение в патогенезе РА.

Адаптивный ответ на острый психический стресс (аллостаз) запускается кортикотропин-рилизинг-гормоном (КРГ), стимуляторами выброса которого являются, в частности, тахикинины (нейрокинины А и В, нейропептид К, субстанция Р). Тахикинины и норадреналин активируют сигнальный путь ядерного фактора каппа-В (NF-кB) и синтез NF-кB-зависимых провоспалительных цитокинов - фактора некроза опухоли $\alpha(\Phi Н О \alpha)$, интерлейкина 1 (ИЛ1) и ИЛ6 в клетках центральной нервной системы (ЦНС). Провоспалительные цитокины также стимулируют секрецию КРГ и активируют продукцию кортизола, ингибирующего NF-кB [12]. КРГ, глюкокортикоиды (ГК), катехоламины и другие участники стрессового ответа подавляют одни и активируют другие механизмы иммунитета во время стресса (рис. 1), что и объясняет разнонаправленные эффекты стресса на возникновение и течение заболеваний, в патогенезе которых участвует иммунная система. Усиленный выброс кортизола по мере развития адаптивного ответа ингибирует выработку КРГ и NF-кB по механизму обратной связи с глюкокортикоидных рецепторов (ГР), парасимпатических нейротрансмиттеров, ФНО $\alpha$, а также ИЛ10 $[12,13]$.

Баланс симпатической и парасимпатической систем. Сбалансированный аллостаз предполагает подавление парасимпатической нервной системы с оперативным возвратом в исходное состояние, причем наиболее высокая постстрессорная активность парасимпатической нервной системы отмечается у лиц, отличающихся высоким уровнем уравновешенности нервных процессов [14].

NF-кB-зависимые провоспалительные цитокины. NFкВ сигнальный путь участвует в передаче информации от активных синапсов к ядру клетки. NF-кB-зависимые факторы, в частности, провоспалительные цитокины ИЛ6, $\Phi H O \alpha$, ИЛ $1 \beta$, играют роль в синаптической пластичности, формировании памяти, пространственной ориентации [15].

При стрессе процессы с участием NF-кB происходят не только в ЦНС, но и на периферии $[12,16]$. C. McInnis и соавт. [12] в экспериментах на здоровых добровольцах выявили стресс-индуцированное увеличение экспрессии генов факторов NF-кB сигнального пути, ИЛ6, ИЛ1 в лейкоцитах сосудистого русла. По данным K. O'Connor и соавт. [16], острый стресс приводит к повышению сывороточных уровней ИЛ $2 \beta$, ИЛ6, ФНО $\alpha$, ИЛ8.

Крайне важными условиями физиологического аллостаза являются интенсивность и продолжительность продукции провоспалительных цитокинов. По данным метаанализа А. Marsland и соавт. [17], концентрация ИЛ1 в крови повышалась немедленно после стрессового воздействия и достигала максимума к 40-50-й минуте, концентрация ФНО $\alpha$ нарастала до максимума к $30-50$-й минуте, затем быстро снижалась, уровень ИЛ6 достигал 
максимума в течение 1,5 ч. Через 2 ч концентрации всех цитокинов возвращались к базальному уровню [17]. При формировании нормального адаптивного ответа нарастание уровней цитокинов в ЦНС и в сосудистом русле происходит пропорционально интенсивности острого стресса [17]. У лиц с выраженной способностью когнитивного контроля эмоциональной информации подъемы уровней ИЛ1, ИЛ6, ИЛ8 в слюне после просмотра эмоционального видео были менее выражены по сравнению с лицами того же пола и возраста с низкой способностью критического осмысления увиденного. В то же время подъемы уровней кортизола в слюне в этих подгруппах имели близкие значения [18].

Кортикотропин-рилизинг-гормон и иммунная система. Воздействие гипоталамического КРГ на иммунную систему опосредуется гипофизарным АКТГ и, в конечном счете, эффекторами стрессовых реакций - продуцируемыми надпочечниками ГК и катехоламинами. Кроме того, КРГ оказывает прямое иммуносупрессивное действие, наиболее уязвимой мишенью которого являются Т-цитотоксические лимфоциты. Это быстрый эффект: после инфузии КРГ снижение активности цитотоксических лимфоцитов селезенки на $50 \%$ отмечается в течение 20 мин, естественных киллеров крови в течение 1 ч. Введение антител к КРГ животным полностью предотвращает эти эффекты [19, 20].

Следует отметить, что КРГ также присутствует непосредственно в очагах бактериального и асептического воспаления (иммунный КРГ) и участвует в формировании этих очагов. Его источником, вероятно, являются периферические нервы [20]. Под влиянием КРГ происходит стресс-индуцированная дегрануляция тучных клеток [20], что приводит к хорошо известным эффектам гистамина в очаге воспаления - расширению сосудов и отеку тканей (рис. 2). Кроме того, гистамин модулирует активность периферических моноцитов, подавляя секрецию ИЛ12 и ФНО $\alpha$ и стимулируя продукцию ИЛ10, ингибирует продукцию интерферона $\gamma(И Ф Н \gamma)$ Th1-лимфоцитами, но не влияет на выработку ИЛ4 Тh2-клонами лимфоцитов, способствуя сдвигу $\mathrm{Th} 1 \rightarrow$ Th2 [20].

Воздействие глюкокортикоидов и катехоламинов на иммунную систему. При реальной или предполагаемой угрозе жизни ГК модулируют энергетические процессы в клетках и тканях для обеспечения выживания клеток и постстрессового восстановления, а также управляют адаптивным ответом на стресс, ингибируя гипоталамо-гипофизарнонадпочечниковую (ГГН) ось [21]. Модулируя активность провоспалительных транскрипционных факто- ров - белка-активатора АР-1 и NF-кB, - они ингибируют пролиферацию, миграцию и цитотоксичность лимфоцитов, подавляют секрецию некоторых цитокинов (ИЛ2, ФНО $\alpha$, ИФНү) и, стимулируя выработку ИЛ10, усиливают трафик лейкоцитов, одновременно ингибируя многие функции, в том числе синтез медиаторов воспаления [21].

Катехоламины, по-видимому, могут оказывать противовоспалительное действие в ЦНС. Норадреналин ингибировал экспрессию NF-кB, интерферонового регуляторного фактора 1 (interferon regulatory factor $1-$ IRF1) и фосфорилирование STAT1 в культурах клеток микроглии [22]. В культурах клеток и в когортах лиц с острой черепно-мозговой травмой с характерным для нее массивным выбросом катехоламинов воздействие этих стрессовых факторов на $\beta$-адренорецепторы, экспрессируемые Th1-, но не Th2-лимфоцитами, приводит к подавлению продукции ИЛ12, ИФН. При этом усиливается секреция ИЛ10 и не меняется выработка ИЛ4 [23]. Вследствие цитокин-опосредованного и прямого воздействия катехоламинов происходит выброс естественных киллеров и цитотоксических лимфоцитов в сосудистое русло при одновременном ингибировании их цитотоксических функций, а также подавляются цитотоксическая активность макрофагов, фагоцитоз и бакте-

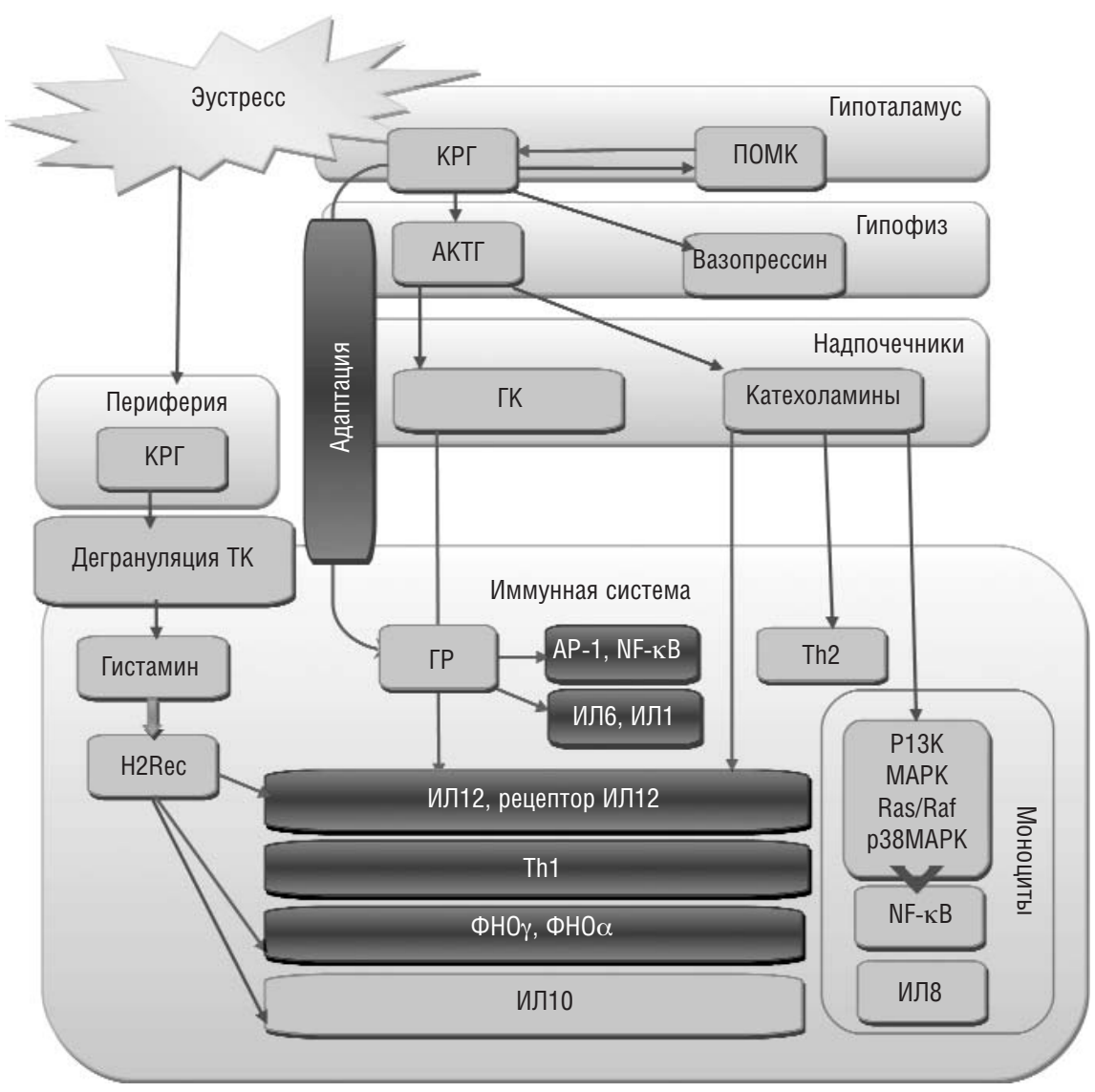

Рис. 1. Эфрфекторы гипоталамо-гипофризарно-надпочечниковой оси и иммунная система под воздействием эустресса: сдвиг баланса Th1 $\rightarrow$ Th2, ингибирование провоспалительных фракторов и обратная сигнализация с ГР (адаптация). Темные прямоугольники - ингибирование, более светлые - активация. ПОМК - проопиомеланокортин, ТК - тучные клетки, PI3K - фоссфоинозитидил-3-киназа, Rec - рецептор, H2Rec - рецептор гистамина Н2. АКТГ - адренокортикотропный гормон, МАРК - митоген-активируемая протеинкиназа, АР - активаторный протеин 
рицидная функция гранулоцитов [23]. Катехоламины ингибируют поликлональную и стимулированную моноклональными антителами к CD3 пролиферацию Т-клеток. Эти эффекты также опосредованы стимуляцией $\beta$-адренорецепторов [23].

Эндогенные опиоиды и иммунная система. Сворачивание антистрессового адаптивного ответа запускается эндогенными опиоидами (ЭО) - эндорфинами, энкефалинами и динорфинами, которые обладают анальгетическим эффектом и ингибируют активность стрессовой системы по механизму обратной связи [24]. Секреция гипофизом опиоидных пептидов индуцируется КРГ и катехоламинами и ингибируется ГК, которые, вероятно, блокируют синтез и процессинг предшественников опиоидных пептидов [24]. ЭО подавляют выработку КРГ и норадреналина, а также АКТГ и ГК [25] и, соответственно, отменяют описанные выше эффекты этих факторов на иммунную систему.

Сбалансированная продукция ЭО и адекватная экспрессия опиоидных рецепторов в рамках нормального адаптивного антистрессового ответа повышают порог болевой чувствительности и определяют устойчивость к грядущим стрессам [26].
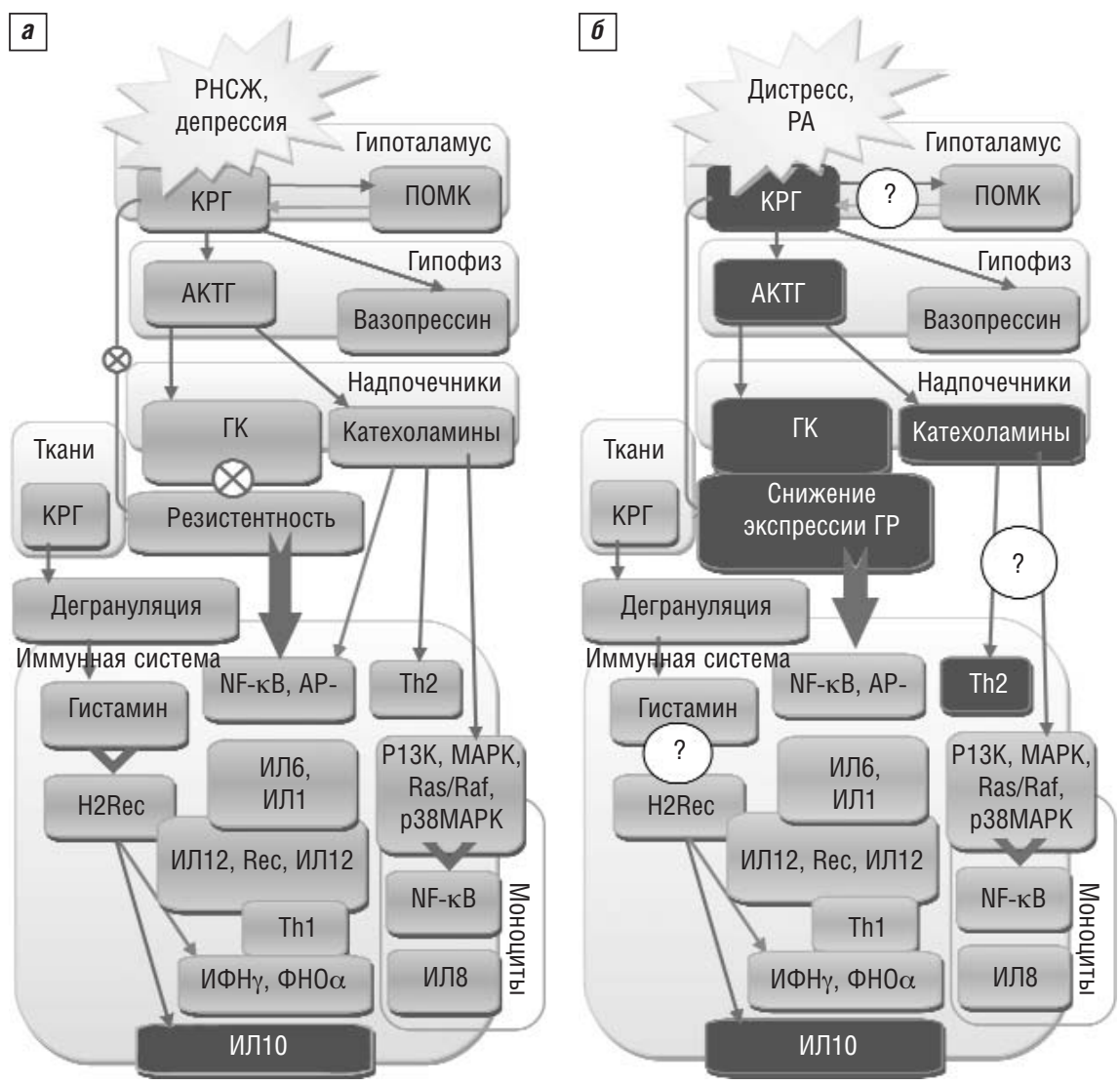

Рис. 2. Реакции ГГН-оси в зависимости от вида стресса. а - гиперактивность ГГН-оси при ранних негативных событиях жизни (РНСЖ) и депрессии: стероидорезистентность, отмена обратной связи с ГР и глюкокортикоидной сигнальной системой, стойкое повышение уровней гормонов стресса и отмена сдвига в сторону Th2 за счет активации NF-кBзависимых провоспалительных цитокинов; б - гипоактивность ГГН-оси при дистрессе и РА: снижение уровня гипоталамического КРГ и гормонов стресса, снижение экспрессии ГР и активация NF-кB-зависимых провоспалительных цитокинов. Темные прямоугольники - ингибирование, более светлые - активация. ПОМК - проопиомеланокортин, PI3K - фросфоинозитидил-3-киназа, Rec - рецептор, H2Rec - рецептор гистамина H2
ЭО продуцируются также гранулоцитами, моноцитами/макрофагами, Т- и В-лимфоцитами в очаге воспаления, в крови, селезенке, лимфатических узлах и в лимфоидной ткани слизистых оболочек [27]. ЭО подавляют функции мононуклеаров крови и способствуют Th1 $\rightarrow$ Th2 сдвигу их активности. Они также снижают активность естественных киллеров, продукцию ИФН $\gamma$ Т-лимфоцитами и липополисахарид-стимулированную пролиферацию В-лимфоцитов, т. е. в целом действуют как иммуносу-

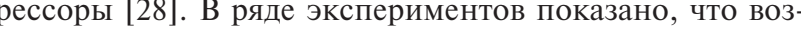
патогенов, снижая при этом цитотоксические функции макрофагов. Это приводит к внутриклеточному размноснию и персистенции патогенов в организме хозяина Воздействие ЭО на мышиные спленоциты приводит к поКроме того, ЭО подавляют хемотаксис клеток иммунной системы и пролиферацию Т- и В-лимфоцитов в селезенке и лимфатических узлах [29].

\section{Общие патогенетические механизмы развития дистресса и ревматоидного артрита}

При сбалансированном аллостазе усиленный выброс одних факторов ингибирует другие по механизму обратной связи и «успокаивает» острые стрессовые реакции. Любое нарушение в этой цепи регуляции приводит к срыву адаптации, развитию дистресса, хронического стресса и соматизации.

Гиперпродукция $\mathrm{NF- \kappa B-зависи-}$ мых провоспалительных цитокинов. В экспериментах на животных показано, что головной мозг особей с пассивной стратегией выживания, в отличие от их активных сородичей, отвечает на стресс более выраженной продукцией ИЛ $1 \beta$, ИЛ6 и ФНО $\alpha$, причем уровни этих цитокинов остаются высокими к 21-му дню после стрессового воздействия [30]. Для таких особей характерно замедленное постстрессовое снижение концентраций провоспалительных цитокинов в крови [31]. Избыточная и затянутая во времени продукция провоспалительных цитокинов в ЦНС и на периферии в ответ на острое стрессовое воздействие является фактором риска развития хронического депрессивного состояния, тревожных расстройств, агрессии, а также ряда нейропсихических заболеваний [32].

Для PA тоже характерна чрезмерная активация NF-кB и Jak/Statсигнальных путей с избыточной и плохо контролируемой продукцией провоспалительных цитокинов за счет аккумуляции точечных мутаций генов этих факторов [33] или воздействия средовых факторов (инфекций) у предрасположенных к развитию РА лиц [34]. 
Гиперактивность ГГН-оси. В отличие от эустресса, при котором уровни стрессовых гормонов быстро возвращаются к нормальным значениям, у 50\% пациентов с депрессией и $80 \%$ пациентов с тяжелой депрессией обнаруживалась гиперактивность ГГН-оси с повышенными уровнями КРГ, АКТГ и ГК (см. рис. 2, а), вероятно, вследствие нарушения механизма обратной связи с ГР [35].

Гипоактивность ГГН-оси. Согласно теории Селье, в своем развитии стресс проходит стадию мобилизации защитных сил, стадию повышения резистентности и либо завершается адаптацией, либо затягивается и приводит к истощению адаптивных механизмов. В последнем случае стресс переходит в декомпенсированную стадию, проявляющуюся клинической депрессией или соматическим заболеванием [3]. Вероятно, в случае неблагоприятного развития антистрессового ответа происходит истощение механизмов образования соответствующих гормонов и нейротрансмиттеров и нарушение механизмов обратной связи между гормонами надпочечников и гипоталамо-гипофизарной системы (см. рис. 2, б). Это приводит к развитию субклинического воспалительного процесса и стойкому, хотя и небольшому повышению уровней провоспалительных цитокинов [36]. Даже умеренный по интенсивности, но длительный психологический стресс приводит к провоспалительным сдвигам в нейроэндокринной системе в связи с отсутствием адекватного ответа со стороны ГГН-оси [37]. Эффекты стресса зависят не только от его продолжительности или интенсивности, но и от генетически обусловленных особенностей ГГН-оси. Эта зависимость была продемонстрирована в исследованиях на крысах Фишера и Льюиса - двух высокоимбредных линиях, устойчивых (Фишер) и восприимчивых (Льюис) к воспалительным заболеваниям [37]. РА-резистентные крысы Фишера демонстрировали гиперактивный стрессовый ответ. У экстремально восприимчивых к Тh1-индуцированным заболеваниям крыс Льюиса антистрессовый ответ ГГН-оси был снижен. Дефект ГГН-оси у крыс Льюиса был локализован в гипоталамических нейронах, секретирующих КРГ, которые не отвечали на стимуляцию нейротрансмиттерами. Кроме того, у этих животных выявлялись хронический подъем уровня вазопрессина и поведение, напоминающее атипическую депрессию у людей состояние, характеризуемое низким уровнем гипоталамической секреции КРГ. Таким образом, недостаточный ответ ГГН-оси в случае дистресса можно объяснить либо истощением нейроэндокринной системы в результате продолжительного изматывающего стресса, либо дефектами самой ГГН-оси.

При РА также продемонстрировано снижение продукции КРГ гипоталамусом - дефект нейроэндокринной регуляции, приводящий к низкой стресс-индуцированной продукции кортизола в ответ на стимуляцию АКТГ [38]. Сниженная продукция гормонов надпочечников предшествует развитию РА [39], может провоцировать дебют РА у пожилых лиц, женщин в пременопаузе и мужчин [40] и находится в обратной корреляции с уровнями ИЛ6 и ФНО $\alpha$ [39].

Дефекты глюкокортикоидных мищеней в тканях. Противовоспалительные и иммуносупрессивные свойства ГК реализуются только в случае их активного и достаточного взаимодействия с рецепторами в клетках. ГР распространены повсеместно, и их количество определяет чувствительность клеток и тканей к ГК.
Ген ГР - NR3C1 - существует в единственном варианте, но известно несколько вариантов сплайсинга его мРНК. Сплайсинг ГР $\alpha$, который преобладает почти во всех тканях и клетках, является лиганд-зависимым фактором ядерной транскрипции. Комплекс ГК-ГР $\alpha$ взаимодействует со специфическими сайтами связывания NF-кB [41] и ингибирует экспрессию генов NF-кB-зависимых цитокинов. ГР $\beta$ экспрессируются в некоторых тканях в значительно более низких концентрациях, не обладают транскрипционной активностью и ингибируют ГР $\alpha$, возможно, конкурируя за GRE-последовательность [42] и отменяя эффекты ГК [41]. Сплайсинговый вариант ГР $\alpha$ составляет 4-8\% от общего количества ГР, но активны лишь 50\% этих рецепторов [43]. Изменения баланса ГР $\alpha / Г Р \beta$ могут вносить вклад в формирование резистентности у пациентов с депрессией. Эмоциональные факторы могут влиять на экспрессию гена NR3C1. Например, у детенышей мышей материнское вылизывание и грумминг изменяли уровень экспрессии ГР путем изменения статуса метилирования промотора гена $N R 3 C 1$, что приводило к изменению реактивности их ГГН-оси [44]. Посмертное исследование мозга жертв суицида, переживших эпизоды детской насильственной травмы в анамнезе, показали увеличение уровня метилирования промотора гена NR3C1 и снижение экспрессии мРНК этих рецепторов [45].

При хронической депрессии изменение функционирования ГР приводит к нарушению обратной связи ГГНоси и к постоянно повышенному уровню КРГ и КС, что было доказано с использованием дексаметазонового теста [46]. Ослабленная ГК-сигнализация не в состоянии обеспечить достаточное ингибирование провоспалительных ядерных транскрипционных факторов. Так, для хронического стресса и депрессии характерна активация NF-кB и JAK/STAT - двух чрезвычайно важных для PA сигнальных путей [47]. Избыточная экспрессия генов NF-кB-сигнального пути выявлена и у лиц, подверженных длительному умеренному стрессу вследствие ухода за больными родственниками [47]. В этой группе отмечалось повышение уровня гормонов стресса, воспалительных цитокинов и С-реактивного белка (СРБ), а также снижение экспрессии генов факторов сигнального пути с ГР, что может отменять характерный для стресса Th1 $\rightarrow$ Th2 сдвиг иммунных реакций. Именно в такой ситуации находятся предрасположенные к развитию РА лица.

При исследовании содержания мРНК в мононуклеарах крови в группе стероид-резистентных больных РА обнаружено значительное увеличение экспрессии ГР $\beta$ и соотношения ГР $\alpha / \Gamma \mathrm{P} \beta$, а также повышение доли ГР $\beta$ протеин-содержащих клеток по сравнению со стероид-чувствительными пациентами [48]. В дополнение к возможным аномалиям экспрессии ГР $\alpha$, вероятно, обусловленным нарушениями во внутриклеточных сигнальных путях и/или ускоренной утилизацией рецепторов, обнаружены РА-ассоциированные точечные мутации генов ГР $\beta$ и ГР $\alpha$ [49].

Дисбаланс тонуса симпатической и парасимпатической систем. Недостаточный выброс катехоламинов и/или недостаточное снижение тонуса парасимпатической нервной системы, затянувшийся сдвиг баланса в сторону симпатической импульсации в ЦНС и на периферии могут привести к развитию депрессии [19]. Эксперименты на мышиных моделях с применением ингибиторов холинэстеразы показали, что повышенный базальный уровень холинергических медиаторов в гиппокампе и отсутствие 
его снижения после воздействия стрессового фактора уменьшают способность справиться со стрессом [19]. Достоверно подтвержден гипотонус парасимпатической нервной системы у больных РА и лиц, предрасположенных к заболеванию [50]. Метаанализ 40 исследований симпатического/парасимпатического баланса показал наличие парасимпатической дисфункции в 77\% публикаций, симпатической - в 53\% [51]. В двух исследованиях обнаружен сниженный ответ симпатической нервной системы на стрессовое воздействие у пациенток с низкой активностью РА в пременопаузе и лиц группы риска [52]. Выявлены также нарушения иммуномодулирующей функции катехоламинов - отсутствие Th $1 \rightarrow$ Th2 сдвига продукции цитокинов при воздействии катехоламинов на Т-лимфоциты, а также снижение катехоламин-индуцированного апоптоза В-лимфоцитов больных РА, возможно, обусловленные нарушенной рецепцией катехоламинов клетками [53].

Гипопродукция эндогенных опиоидов. Неспособность ответить адекватным повышением продукции ЭО в рамках аллостаза снижает устойчивость к воздействию стресса и способствует развитию дистресса. В большинстве исследований показано снижение уровней ЭО в крови и цереброспинальной жидкости больных РА [54]. Выявлена обратная корреляция уровней ЭО в сыворотке и клетках крови с активностью и тяжестью течения РА [54]. ЭО могут подавлять продукцию ФНО $\alpha$ и ИЛ $1 \beta$ на уровне экспрессии мРНК, а также продукцию матриксной металлопротеиназы 9 клетками синовиальной оболочки больных РА [55]. Введение $\beta$-эндорфина крысам с коллаген-индуцированным артритом подавляло экспресссию мРНК ряда провоспалительных цитокинов, хемокинов и матриксных металлопротеиназ в синовиальной оболочке, отменяло сдвиг Th1/Th2-баланса в сторону Th1 и обрывало или существенно облегчало клинические проявления артрита [56]. В то же время в ревматоидной синовиальной оболочке обнаружены избыточные концентрации продуцируемых лейкоцитами эндорфина и энкефалина, а также гиперэкспрессия мю-опиоидных рецепторов на различных типах клеток [57].

Инфекционная составляющая при стрессе и ревматоидном артрите. Для сбалансированного аллостаза, эволюционирующего от стадии мобилизации к стадии адаптации, характерен Th1 $\rightarrow$ Th2-сдвиг иммунных реакций. Это свидетельствует как минимум об отсутствии какого-либо прямого участия эустресса в развитии такого Th1-опосредованного заболевания, как РА, тогда как при дистрессе этот сдвиг может отменяться и даже изменять направление

\section{Л И Т Е Р А Т У Р А}

1. Kobayashi S, Momohara S, Kamatani N, et al. Molecular aspects of rheumatoid arthritis: role of environmental factors. FEBS J. 2008;275(18):4456-62. doi: 10.1111/j.17424658.2008.06581.x

2. Arleevskaya M, Kravtsova O, Lemerle J, et al. How Rheumatoid Arthritis Can Result from Provocation of the Immune System by Microorganisms and Viruses. Frontiers in Microbiology. 2016; 7:1296. doi: 10.3389/fmicb.2016.01296

3. Горизонтов ПД. Гомеостаз. Москва: Медицина; 1981. 576 с. [Gorizontov PD. Gomeostaz [Homeostasis]. Moscow: Meditsina; 1981. 576 p. (In Russ.)]

4. Korshunov NI, Grigor'eva EA, Kapustina LV, et al. The problems, mental disorders and quality of life of rheumatoid arthritis patients. Ter Arkh. 1991;63(8):100-4. (см. рис. 2). Однако индуцированные эустрессом сдвиги в иммунной системе могут иметь серьезные последствия для восприимчивости организма к инфекциям [58]. В ряде исследований показана связь стресса с инфекциями, вызванными риновирусами 2, 9, 14-го типов, респираторносинцитиальным вирусом, коронавирусом 229Е-типа, парвовирусами [58, 59], герпес-вирусами [59]. Результаты исследований, проводимых нашим научным коллективом, свидетельствуют о возможной роли часто рецидиврующих острых респираторных вирусных инфекций в возникновении РА и в поддержании его активности [34, 60]. Однако вряд ли единичный эпизод реактивации инфекции, индуцированный нормальным ответом на острый стресс, спровоцирует развитие РА, разве что этот эпизод будет последней каплей в череде провокаций иммунной системы генетически предрасположенного к заболеванию организма.

\section{Заключение}

При детальном анализе выявляется определенный синергизм механизмов развития дистресса, депрессии и РА. Среди них ярко выделяются: избыточная активация NF-кB-сигнального пути с гиперпродукцией провоспалительных цитокинов, особенности функционирования ГГН-оси со сниженной продукцией ГК, снижение экспрессии ГР с развитием стероидорезистентности. Эти особенности также могут отменить или ослабить Th1 $\rightarrow$ Th2сдвиг при остром стрессе и способствовать развитию дистpecca. Дистресс может приводить к дисбалансу симпатической и парасимпатической систем еще в доклинической стадии РА. Можно предположить, что у лиц группы риска развития этого заболевания минимальные и, возможно, малозаметные для индивидуума стрессовые ситуации, периодически провоцирующие продолжительную продукцию провоспалительных цитокинов, могут в конце концов привести к развитию ревматического заболевания.

\section{Прозрачность исследования}

Исследование поддержано грантом Российского научного фонда (№. 17-15-01099). Авторы несут полную ответственность за предоставление окончательной версии рукописи в печать.

Декларация о финансовых и других взаимоотношениях

Все авторы принимали участие в разработке концепции статьи и в написании рукописи. Окончательная версия рукописи была одобрена всеми авторами. Авторы не получали гонорар за статью.
5. Hanly J, Fisk J, McCurdy G. Neuropsychiatric syndromes in patients with systemic lupus erythematosus and rheumatoid arthritis. J Rheumatol. 2005;32(8):1459-66.

6. Lu M, Guo H, Lin M, at al. Bidirectional associations between rheumatoid arthritis and depression: a nationwide longitudinal study. Scientific Reports. 2016;6(1):20647. doi: $10.1038 /$ srep20647

7. Farmer A, Korszun A, Owen M, et al. Medical disorders in people with recurrent depression. Brit J Psychiatry. 2008;192(05):351-5. doi: 10.1192/bjp.bp.107.038380

8. Van't Land H, Verdurmen J, ten Have M, et al. The association between arthritis and psychiatric disorders; results from a longitudinal population-based study. J Psychosomat Res. 2010;68(2):18793. doi: 10.1016/j.jpsychores.2009.05.011 
9. Sö derlin M, Bergsten U, Svensson B, for the BARFOT study group. Patient-reported events preceding the onset of rheumatoid arthritis: Possible clues to aetiology. Musculoskeletal Care. 2010;9(1):25-31. doi: 10.1002/msc. 193

10. Rezvani A, Aytü re L, Arslan M, et al. Affective temperaments in patients with rheumatoid arthritis. Int J Rheum Dis. 2014;17(1):348. doi: 10.1111/1756-185X.12033

11. Gadek-Michalska A, Tadeusz J, Rachwalska P, et al. Cytokines, prostaglandins and nitric oxide in the regulation of stress-response systems. Pharmacol Rep. 2013;65(6):1655-62. doi: 10.1016/S17341140(13)71527-5

12. McInnis C, Wang D, Gianferante D, et al. Response and habituation of pro- and anti-inflammatory gene expression to repeated acute stress. Brain Behav Immun. 2015;46:237-48. doi: 10.1016/j.bbi.2015.02.006

13. Szabo Y, Newton T, Miller J, et al. Acute stress induces increases in salivary IL-10 levels. Stress. 2016;19(5):499-505. doi: $10.1080 / 10253890.2016 .1206885$

14. Щербатых ЮВ. Влияние параметров высшей нервной деятельности студентов на характер протекания экзаменационного стресса. Журнал высшей нервной деятельности им. И.П. Павлова. 2000;(6):959-65 [Shcherbatykh YuV. The influence of the parameters of the higher nervous activity of students on the nature of the exam stress. Zhurnal Vysshey Nervnoy Deyatel'nosti im. I.P. Pavlova. 2000;(6):959-65 (In Russ.)].

15. Snow W, Stoesz B, Kelly D, et al. Roles for NF-кB and Gene Targets of NF-кB in Synaptic Plasticity, Memory, and Navigation. Mol Neurobiol. 2013;49(2):757-70. doi: 10.1007/s12035-013-8555-y

16. O'Connor K, Johnson J, Hansen M, et al. Peripheral and central proinflammatory cytokine response to a severe acute stressor. Brain Res. 2003;991(1-2):123-32. doi: 10.1016/j.brainres.2003.08.006

17. Marsland A, Walsh C, Lockwood K, et al. The effects of acute psychological stress on circulating and stimulated inflammatory markers: A systematic review and meta-analysis. Brain Behav Immun. 2017;64:208-19. doi: 10.1016/j.bbi.2017.01.011

18. Shields G, Kuchenbecker S, Pressman S, et al. Better cognitive control of emotional information is associated with reduced proinflammatory cytokine reactivity to emotional stress. Stress. 2016;19(1):63-8. doi: 10.3109/10253890.2015.1121983

19. Fernandes S, Koth A, Parfitt G, et al. Enhanced cholinergictone during the stress induce a depressive-like state in mice. Behav Brain Res. 2018;347:17-25. doi: 10.1016/j.bbr.2018.02.044

20. Theoharides T, Spanos C, Pang X, et al. Stress-induced intracranial mast cell degranulation: a corticotropin-releasing hormonemediated effect. Endocrinology. 1995;136(12):5745-50. doi: 10.1210 /endo.136.12.7588332

21. Herman J, McKlveen J, Solomon M, et al. Neural regulation of the stress response: glucocorticoid feedback mechanisms. Braz J Med Biol Res. 2012;45(4):292-8. doi: 10.1590/S0100-879X2012007500041

22. Ishii Y, Yamaizumi A, Kawakami A, et al. Anti-inflammatory effects of noradrenaline on LPS-treated microglial cells: Suppression of NFKB nuclear translocation and subsequent STAT1 phosphorylation. Neurochem Int. 2015;90:56-66. doi: 10.1016/j.neuint.2015.07.010

23. Elenkov I, Chrousos G. Stress Hormones, Th1/Th2 patterns, Pro/Anti-inflammatory Cytokines and Susceptibility to Disease. Trends Endocrinol Metabolism. 1999;10(9):359-68. doi: 10.1016/S1043-2760(99)00188-5

24. Bicknell R. Endogenous opioid peptides and hypothalamic neuroendocrine neurones. J Endocrinol. 1985;107(3):437-46. doi: $10.1677 /$ joe. 0.1070437

25. Pfeiffer A, Herz A. Endocrine Actions of Opioids. Horm Metabol Res. 1984;16(08):386-97. doi: 10.1055/s-2007-1014801

26. Henry M, Gendron L, Tremblay M, et al. Enkephalins: Endogenous Analgesics with an Emerging Role in Stress
Resilience. Neural Plast. 2017;2017:1-11. doi: $10.1155 / 2017 / 1546125$

27. Plein L, Rittner H. Opioids and the immune system - friend or foe. Brit J Pharmacol. 2017;175(14):2717-25. doi: $10.1111 /$ bph. 13750

28. Ninkovic J, Roy S. Role of the mu-opioid receptor in opioid modulation of immune function. Amino Acids. 2011;45(1):9-24. doi: 10.1007/s00726-011-1163-0

29. McLaughlin P, McHugh D, Magister M, et al. Endogenous opioid inhibition of proliferation of $\mathrm{T}$ and $\mathrm{B}$ cell subpopulations in response to immunization for experimental autoimmune encephalomyelitis. BMC Immunol. 2015;16(1):24. doi: 10.1186/s12865-015-0093-0

30. Joana P, Amaia A, Arantza A, et al. Central immune alterations in passive strategy following chronic defeat stress. Behav Brain Res. 2016;298:291-300. doi: 10.1016/j.bbr.2015.11.015

31. Pertsov S, Koplik E, Stepanyuk V, et al. Blood Cytokines in Rats with Various Behavioral Characteristics during Emotional Stress and Treatment with Interleukin-1 $\beta$. Bull Exper Biol Med. 2009;148(2):196-9. doi: 10.1007/s10517-009-0668-y

32. Aschbacher K, Epel E, Wolkowitz O, et al. Maintenance of a positive outlook during acute stress protects against pro-inflammatory reactivity and future depressive symptoms. Brain Behav Immun. 2012;26(2):346-52. doi: 10.1016/j.bbi.2011.10.010

33. Swierkot J, Nowak B, Czarny A, et al. The Activity of JAK/STAT and NF- $\kappa \mathrm{B}$ in Patients with Rheumatoid Arthritis. Adv Clin Exper Med. 2016;25(4):709-17. doi: $10.17219 /$ acem/61034

34. Arleevskaya M, Shafigullina A, Filina Y, et al. Associations between Viral Infection History Symptoms, Granulocyte Reactive Oxygen Species Activity, and Active Rheumatoid Arthritis Disease in Untreated Women at Onset: Results from a Longitudinal Cohort Study of Tatarstan Women. Frontiers Immunol. 2017;8:1725. doi: 10.3389/fimmu.2017.01725

35. Anacker C, Zunszain P, Carvalho L, Pariante C. The glucocorticoid receptor: Pivot of depression and of antidepressant treatment? Psychoneuroendocrinology. 2011;36(3):415-25. doi: 10.1016/j.psyneuen.2010.03.007

36. Gouin JP, Glaser R, Malarkey WB, et al. Childhood abuse and inflammatory responses to daily stressors. Ann Behav Med. 2012;44(2):287-92. doi: 10.1007/s12160-012-9386-1

37. Chrousos G, Torpy D, Gold P. Interactions between the Hypothalamic-Pituitary-Adrenal Axis and the Female Reproductive System: Clinical Implications. Ann Intern Med. 1998;129(3):229. doi: 10.7326/0003-4819-129-3-19980801000012

38. Cutolo M, Sulli A, Pizzorni C, et al. Hypothalamic-PituitaryAdrenocortical and Gonadal Functions in Rheumatoid Arthritis. Ann N Y Acad Sci. 2003;992(1):107-17. doi: 10.1111/j.17496632.2003.tb03142.x

39. Straub R, Paimela L, Peltomaa R, et al. Inadequately low serum levels of steroid hormones in relation to interleukin-6 and tumor necrosis factor in untreated patients with early rheumatoid arthritis and reactive arthritis. Arthritis Rheum. 2002;46(3):654-62. doi: 10.1002/art.10177

40. Masi A, Rehman A, Chatterton R, et al. Controlled Cohort Study of Serum Gonadal and Adrenocortical Steroid Levels in Males Prior to Onset of Rheumatoid Arthritis (pre-RA): A Comparison to pre-RA Females and Sex Differences among the Study Groups. Intern J Rheumatol. 2013;2013:1-11. doi: $10.1155 / 2013 / 284145$

41. Neeck G, Klü ter A, Dotzlaw H, et al. Involvement of the Glucocorticoid Receptor in the Pathogenesis of Rheumatoid Arthritis. Ann N Y Acad Sci. 2002;966(1):491-5. doi: 10.1111/j.1749-6632.2002.tb04252.x

42. Fruchter O, Kino T, Zoumakis E, et al. The Human Glucocorticoid Receptor (GR) Isoform $\beta$ Differentially Suppresses GR $\alpha$-Induced Transactivation Stimulated by Synthetic Glucocorticoids. J Clin Endocrinol Metabol. 2005;90(6):3505-9. doi: $10.1210 /$ jc. $2004-1646$ 
43. Duma D, Jewell C, Cidlowski J. Multiple glucocorticoid receptor isoforms and mechanisms of post-translational modification. J Steroid Biochem Mol Biol. 2006;102(1-5):11-21. doi: 10.1016/j.jsbmb.2006.09.009

44. Weaver I, Cervoni N, Champagne F, et al. Epigenetic programming by maternal behavior. Nat Neurosci. 2004;7(8):847-54. doi: $10.1038 / \mathrm{nn} 1276$

45. McGowan P, Sasaki A, D'Alessio A, et al. Epigenetic regulation of the glucocorticoid receptor in human brain associates with childhood abuse. Nat Neurosci. 2009;12(3):342-8. doi: $10.1038 / \mathrm{nn} .2270$

46. Stockman J. Association of FKBP5 Polymorphisms and Childhood Abuse With Risk of Posttraumatic Stress Disorder Symptoms in Adults. Yearbook Pediatr. 2009;2009:103-4. doi: 10.1016/S0084-3954(08)79072-9

47. Miller G, Murphy M, Cashman R, et al. Greater inflammatory activity and blunted glucocorticoid signaling in monocytes of chronically stressed caregivers. Brain Behav Immun. 2014;41:1919. doi: 10.1016/j.bbi.2014.05.016

48. Kozaci D, Chernajovsky Y, Chikanza I. The differential expression of corticosteroid receptor isoforms in corticosteroid-resistant and -sensitive patients with rheumatoid arthritis. Rheumatology. 2006;46(4):579-85. doi: 10.1093/rheumatology/kel276

49. Van Oosten M, Dolhain R, Koper J, et al. Polymorphisms in the glucocorticoid receptor gene that modulate glucocorticoid sensitivity are associated with rheumatoid arthritis. Arthritis Res Ther. 2010;12(4):R159. doi: 10.1186/ar3118

50. Koopman F, Tang M, Vermeij J, et al. Autonomic Dysfunction Precedes Development of Rheumatoid Arthritis: A Prospective Cohort Study. EBioMedicine. 2016;6:231-7. doi: 10.1016/j.ebiom.2016.02.029

51. Adlan A, Lip G, Paton J, et al. Autonomic function and rheumatoid arthritis - A systematic review. Semin Arthritis Rheum. 2014;44(3):283-304. doi: 10.1016/j.semarthrit.2014.06.003
52. Rovensky J, Imrich R, Penesova A, et al. Adrenomedullary Response to Hypoglycemia in First-degree Relatives of Patients with Rheumatoid Arthritis. Ann N Y Acad Sci. 2008;1148(1):552-5. doi: 10.1196/annals. 1410.070

53. Wahle M, Hanefeld G, Brunn S, et al. Failure of catecholamines to shift T-cell cytokine responses toward a Th2 profile in patients with rheumatoid arthritis. Arthritis Res Ther. 2006;8(5):R138. doi: $10.1186 /$ ar2028

54. Elbeialy A, Elbarbary M, Kamel M. Peripheral Beta-Endorphin in Rheumatoid Arthritis: A Correlation with the Disease Activity. Scand J Rheumatol. 1997;26(2):88-91. doi: 10.3109/03009749709115824

55. Takeba Y, Suzuki N, Kaneko A, et al. Endorphin and enkephalin ameliorate excessive synovial cell functions in patients with rheumatoid arthritis. J Rheumatol. 2001;28(10):2176-83.

56. Yin H, Zhang F, Yu M, et al. Beta-Endorphin Ameliorates Synovial Cell Hyperfunction in the Collagen-Induced Arthritis Rat Model by Specific Downregulation of NF-kappa B Activity. Neuroendocrinology. 2005;81(1):10-8. doi: 10.1159/000084828

57. Mousa S, Straub R, Schafer M, Stein C. Beta-endorphin, Metenkephalin and corresponding opioid receptors within synovium of patients with joint trauma, osteoarthritis and rheumatoid arthritis. Ann Rheum Dis. 2007;66(7):871-9. doi: 10.1136/ard.2006.067066

58. Maxwell L, Barrett B, Chase J, et al. Self-Reported Mental Health Predicts Acute Respiratory Infection. WMJ. 2015;114(3):100-4.

59. Grinde B. Herpesviruses: latency and reactivation - viral strategies and host response. J Oral Microbiol. 2013;5(1):22766. doi: 10.3402/jom.v5i0.22766

60. Arleevskaya M, Gabdoulkhakova A, Filina Y, et al. A transient peak of infections during onset of rheumatoid arthritis: a 10-year prospective cohort study. BMJ Open. 2014;4(8):e005254. doi: 10.1136/bmjopen-2014-005254 